\title{
Sağlık Yöneticilerinin Liderlik Özellikleri
}

\author{
DOI: $10.26466 /$ opus.555047
}

\author{
Hamide Nur Çevik Özdemir*-Rahman Çakır** _ Rıdvan Küçükali *** \\ * Arş.Gör.Dr., Afyonkarahisar Sağlık Bilimleri Üniversitesi Afyonkarahisar/Türkiye \\ E-Posta: hncevik@aku.edu.tr ORCID: 0000-0002-1199-8801 \\ ** Dr .Öğr. Üyesi, Giresun Üniversitesi Eğitim Fak. Temel Eğitim Bölümü Giresun/Türkiye \\ E-Posta: rahman.cakir@giresun.edu.tr ORCID: 0000-0003-1752-3855 \\ *** Doç.Dr.,Atatürk Üniversitesi Edebiyat Fakültesi Felsefe Bölümü Erzurum /Türkiye \\ E-Posta: ridvankucukali@atauni.edu.tr ORCID: 0000-0001-7254-3723
}

\section{Öz}

Sağllk hizmetlerindeki gelişim ve değişim, sağllk kurumlarının yapısl, amaçları ve işleyişleri üzerinde etkili olmaktadır. Bu durum sağlık kurumlarındaki yöneticilerin de liderlik özellikleri göstermesini gerekli kılmaktadır. Bu çalışmada, sağlık kurumlarındaki yöneticilerin liderlik özelliklerinin incelenmesi amaçlanmıştır. Çalışma literatür incelemesi olup, kesitsel-tanımlayıcı niteliktedir. Çalışmalara YÖK Tez veri tabanından, "liderlik, sağllk, yönetici" anahtar sözcükleriyle erişim sağlanmıştır. Verilerin özetlenmesinde PRISMA-P 2015 klavuzu kullanılmıştır. Literatürdeki çalışmaların büyük çoğunluğunun yüksek lisans tezlerinden oluştuğu, genellikle İstanbul ilindeki kamuya bağgl hastanelerde gerçekleştirildiği tespit edilmiştir. Çalışmalarda să̆llk yöneticilerinin dönüşümcü, otantik, etkileşimci liderlik gibi liderlik davranışlarının belirlenmeye çalışıldığg saptanmıştır. İncelenen çalışmaların sonuçları sağlık kurumlarında etkili ve etkin klinik liderlere gereksinim olduğunu ortaya koymaktadır. Sağlık yöneticilerinin liderlik becerilerini geliştirmeye yönelik, hizmet içi eğitim programlarının düzenlenmesi, lisans eğitiminde liderlik konulu ders müfredatlarının oluşturulması önerilebilir.

Anahtar Kelimeler: Sağlık, Sağlık Yöneticisi, Liderlik, Klinik Liderlik. 


\title{
Leadership Characteristics of Health Managers
}

\begin{abstract}
Development and change in health services have an impact on the structure, objectives and functioning of health institutions. This situation requires managers in health institutions to show leadership characteristics. In this study, it is aimed to examine the leadership characteristics of managers in health institutions. The study is a literature review and is cross-sectional. The studies were accessed through the key words "leadership, health, manager" from YÖK Thesis database. PRISMA-P 2015 guide was used to summarize the data. It has been determined that the majority of the studies in the literature consist of master's theses and are generally carried out in public hospitals in Istanbul. In the studies, it was determined that leadership behaviors of health managers such as transformational, authentic and interactive leadership were tried to be determined. The results of the study reveal the need for effective and effective clinical leaders in health institutions. It may be suggested to organize in-service training programs to develop leadership skills of health managers and to create curriculum for leadership in undergraduate education.
\end{abstract}

Keywords: Health, Health Manager, Leadership, Clinical Leadership. 


\section{Giriş}

Sağlık hizmetlerindeki hızlı değişimler, gelişmiş ve üretken toplum yaratma çabası, karmaşık teknolojilerin kullanılması, rekabetin artması, yoğun insan ilişkilerinin yer alması sağlık kurumlarındaki yöneticilerin liderlik davranışları göstermesini gerekli kılmaktadır. Liderlik kavramı, bir grup insanı belirli amaçlar etrafında toplayabilme, bu amaçlar doğrultusunda harekete geçirebilme bilgisi ve yeteneği olarak tanımlanmaktadır (Ardahan ve Konal, 2017; Yılmaz ve Kantek, 2016). Liderlik diğerlerinin göremediği fırsatları fark etme ve bu fırsatları organizasyon yararına kullanabilmedir. Liderler, belirli bir vizyon çerçevesinde diğerlerini etkileyerek onların istekle çalışmasını sağlar (Ardahan ve Konal, 2017; Serinkan ve İpekçi, 2005). Bütün liderlikle ilgili tanımlara bakıldığında genelde ortak nokta olarak etki, vizyon, harekete geçirme, süreç, yönlendirme ve misyon gibi kavramlar ortaya çıkmaktadır (Yavuz, 2015). İyi bir yönetici kendisi ile beraber çalışan diğer bireyleri etkiliyemezse o kurum içerisinde bir takım problemlerin ortaya çıkması kaçınılmaz olacaktır.

Yöneticilerin içinde bulunduğu şartlar altında gösterdiği liderlik davranışları liderlik tarzı olarak tanımlanır. Yöneticilerin kişisel özellikleri, hedef kitlenin niteliği, yöneticinin sahip olduğu liderlik gücü, organizasyondaki pozisyonu liderlik tarzlarının ortaya çıkmasında etkilidir (Yılmaz ve Kantek, 2016). Güç ve etki kavramı dikkate alındığında iki lider tipi ortaya çıkmaktadır. Formal lider; otoritesi sayesinde grup üzerinde etkili olur. İnformal lider ise; otoritesi sayesinde yönettiği grupla bütünleşir. Bu ifadelerden anlaşılacağ 1 gibi liderlik statüden çok kişilik özelliklerine dayalıdır. Bunun için örgütlerin gelişmesinde liderin davranışları etkili olmaktadır. Çünkü lider hem örgütün varlığı açısından gerekli hem de o örgütün devamlılığı için olması gereken etkili bir unsurdur (Yavuz,2015). Ancak liderlik yaklaşımları örgütün içinde bulunduğu şartlara göre örgüt ve yönetim kuramları açısından değişiklik gösterecektir. Bu bağlamda liderlik tarzı kurumun kendi kültürünü de etkiliyerek diğer kişi ve kurumlar tarafından o liderin ortaya koyduğu etkilik biçimine göre algılanmasını sağlayacaktır.

Sağlıkta liderlik, hasta ya da sağlam bireye, bakımın ve tedavinin sağlanmasında belirli amaçlara ulaşabilmek için sağlık yöneticilerinin 
diğer sağlık çalışanlarını etkilediği bir süreçtir. Klinik liderlik ise; bir sağlık kurumundaki, bölümündeki, birimindeki klinisyenlerin, hastaya birebir hizmet sunumunun yanı sıra bu hizmet sunumunun çok daha iyi olması için gayret göstermesi ve bu gayretle politikaları, prosedürleri ve sistemleri değiştirme gücü ve yeteneğidir (Budak ve Özer, 2017). Her kurumun ve her bireyin kendine özgü bir liderlik anlayışı ve bu anlayışı uygulayabilme özelliği vardır. Günümüzde gelişen ve değişen sağlık kurumları, sağlık alanındaki rekabetleşme, sağlıkta özelleşme gibi faktörler nedeniyle artık sağlık hizmetlerinin tüm kademelerindeki yöneticilerden liderlik davranışlarını gösterebilmesi beklenmektedir. Sağlık yöneticilerinin liderlik özellikleri bireysel ve kurumsal başarıda önemli bir etkendir (Duygulu ve Kubilay, 2008). Sağlık hizmetlerinin sunumunda yöneticilik ve liderliğin önemi büyüktür. Sağlık kurumları ve sağlık sistemleri büyük ve karmaşık yapılardır. Bu nedenle sağlık hizmeti sunan personelin iş birliği yapması, uyum göstermesi ve faaliyetlere koordine edilmesi gerekmektedir. İşbirliğinin sağlanıp sürdürülmesi içinde yöneticilerin liderlik davranışlarını etkin bir şekilde gösterip, kullanabilmeleri gerekmektedir (Ardahan ve Konal, 2017). Bu kurumlarda personeller arasındaki uyumun artırılması ve koordinasyonun sağlanmasında etkin olan kişi sağlık liderleridir.

Sağlık kurumlarındaki yöneticilerin sergiledikleri olumlu liderlik davranışları arttıkça, çalışanların performansı, iş doyumu ve hizmet kaliteleri üzerindeki etkileri de pozitif olmaktadır. Yönetimsel süreçler ve politikalar, başarılı liderlik davranışlarıyla sağlık çevresine yeni bir bakış açısı getirmekte, sağlık kurumlarında kaliteyi arttırarak, hastalar ve çalışanlar için yararlı ortamlar oluşturabilmektedir (Lombardi, 2017).

Bu bağlamda bir çok liderlik tipinden bahsetmek mümkün olacaktır. Özellikle sağlık liderliği ile ilgili yapılan çalışmalarda öne çıan en önemli liderlik tiplerinden birisi dönüşümcü liderliktir. Çünkü toplumdaki değişimin hızlı olduğu dönemlerde ve sosyoekonomik sorunların artığı kriz ortamlarında dönüşümcü liderlik en etkili liderlik biçimidir (Gedikoğlu, 2015). Özellikle bu dönemlerde dışarıdan gelen taleplerin karşılanması ve diğer örgütlerde ortaya çıkan olumlu değişikliklerin yakalanması açısından dönüşümcü liderliğe ihtiyaç vardır. Ayrıca bu anlamda etkileşimci liderlikte önemlidir. Etkileşimci lider kendi dışındaki çalışanları izler ve onların performanslarını değerlendirerek, bir işi ne 
kadar iyi yapıp yapmadıklarını belirler. Yaptığı değerlendirme sonucunda başarılı olanları takdir ederek ödüllendirir veya yetersiz olanları belirleyerek onların bu yetersizliklerini gidermeye çalışır. Özellikle sağlik sektöründe hata yapma riskinin olumsuz sonuçlara yol açacağını düşündüğümüzde sağlık personelinin eğitilmesinin önemi bir kat daha artmaktadır (Gedikoğlu, 2015). Bu bağlamda personelin yetiştirilmesi açısından etkileşimci liderlerin varlığı daha da önem arz etmektedir.

Bir başka liderlik biçimi de paternalist liderdir. Çalışan ile lider arasındaki ilişki çok önemlidir. Burada lider çalışanını koruyup gözetir. Hatta bunu sadece iş ortamında yapmaz özel hayatında da yapar. Çalışanda bu durumu gönüllü olarak kabul eder. Paternalist liderliğin üç önemli boyutu vardır (Korkmaz, Gökdeniz ve Zorlu, 2018). Bunlar; yardımseverlik, ahlakilik ve otoriterliktir. Örgüt içerisinde çalışanlarla ilgelenen bir başka liderlik türü de demokratik liderliktir. Demokratik lider çalışanların görüşlerini alır ve uygulamada bunlarada yer verir. Böylece örgüt içi çatışmaları engellemiş olur. Ayrıca demokratik liderler, örgüt çalışanlarının moral ve motivasyonunu yükselterek çalışma gücünü de artırmış olur (Ada ve Küçükali, 2018).

Liderin kişisel özellikleri de önemlidir. Bir başka liderlik tipi olarak otantik liderler bu kapsamda değerlendirilir. Çünkü otantik lider başkalarını taklit etmeyen, kendi beklentilerinden ziyade başkalarının onur ve haysiyetini koruyan, onları motive eden, orjinal görüş ve düşüncelere önem veren, kişisel inanç ve değerlere saygı duyan bir kişidir (Cemaloğlu, 2013). Ayrıca bu bağlamda hizmetkar liderler de önemlidir. Bu liderler, çalışanları ortak amaçlar doğrultusunda toplayıp, onlara yol ve yön gösterirler. Hizmetkar lider, çalışanına rehberlik yapan, örgütün çalışanlarını harekete geçiren ve hizmet eden kişidir (Cemaloğlu, 2013). Son olarakta çalışanların tanınması ve buna göre örgüt yapısının oluşturulmasını sağlayan liderler de görev odaklı lider olarak tanımlanmaktadır (Ergün, Çelik, 2015). Bütün bu liderlik biçimlerinden anlaşılacağ1 gibi liderin başarılı olması örgütün, kurumun ve ekibinin özelliklerini tanımasına ve buna göre bir liderlik yaklaşımı geliştirmesine bağlıdır.

Bu çalışmanın amacı sağlık kurumlarındaki yöneticilerin liderlik özelliklerinin incelenmesidir.

\section{Yöntem}


Çalışma literatür incelemesi olup, kesitsel-tanımlayıcı niteliktedir. Çalışmalara Yüksek Öğretim Kurumu (YÖK) Ulusal Tez veri tabanından erişim sağlanmıştır. Çalışmada, 1998 ile 2018 yılları arasında yapılan ulusal literatürler taranarak bütünlük oluşturulmuştur. Söz konusu çalışmalara ulaşabilmek için tarama yapılırken "liderlik, sağlık, yönetici" anahtar sözcükleri kullanılmıştır. Çalışmalar için tarih kısıtlaması yapılmamıştır. Araştırmaya dahil edilme kriterleri; ulusal bir çalışma olması, örneklemin sağlık alanında çalışan sağlık yöneticilerinden (hekim, yönetici hemşire, klinik sorumlusu vb.) oluşması, çalışmalarda liderlik tarzlarının incelenmesi ve tam metin formatlarına erişilebilir olmasıdır. Elektronik arama ile saptanan ilgili tüm yazıların başlık ve özetleri, araştırmacılar tarafından bağımsız olarak gözden geçirilmiştir. Verilerin toplanmasında Kartal ve Kantek (2015) tarafından hazırlanan veri kodlama formu referans alınarak, verilerin analizi, verilerin özetlenmesi için standart bir veri özetleme formu geliştirilmiştir. Ayrıca çalışmaların özetlenmesinde sistematik incelemelerde geçerli ve güvenilir bir kılavuz olan PRISMA-P 2015 (Preferred reporting items for systematic reviews and meta analyses statement) kullanılmıştır. PRISMA sistematik derleme ve meta-analiz çalışmalarının raporlandırılmasında kullanılan bir kontrol listesidir (www.prisma-statement.org). Araştırmanın nicel verileri SPSS 21.0 paket programı kullanılarak analiz edilmiştir.

\section{Bulgular}

Literatür incelendiğinde, ülkemizde sağllk alanındaki yöneticilerin liderlik özellikleriyle ilgili çalışmaların 1980'li yılların sonundan başlayarak, günümüze kadar artarak devam ettiği görülmektedir. Literatür taramasındaki çalışmaların büyük çoğunluğu yüksek lisans, diğerleri ise doktora tezlerinden oluşmaktadır. Çalışmaların tamamının tanımlayıcı tipte olduğu belirlenmiştir. Araştırmalar İstanbul, Ankara, Kocaeli, Trabzon gibi il merkezlerinde gerçekleştirilmiş olup, yarısından fazlası İstanbul ilindeki kamuya bağlı hastanelerde yapılmıştır. Çalışmaların örneklem grupları incelendiğinde; 26 çalışmanın örneklemini yönetici hemşireler, sorumlu hemşireler ve servis hemşireleri oluştururken, 5 çalışmanın örneklemini ise sağlık yöneticileri, sağlık ku- 
rumlarındaki liderler ve sağlık kurumlarındaki çalışanlar oluşturmaktadır. Çalışmalar kamu hastanesi, üniversite hastanesi ve özel hastane gibi kurumlarda yapılmıştır. Araştırmalarda veri toplama aracı olarak anket formları (çok faktörlü liderlik anketi, liderlik yönelim anketi), liderlik ölçekleri (dönüşümcü liderlik ölçeği, liderlik davranışları ölçeği, stratejik liderlik ölçeği, paternalist liderlik ölçeği) kullanılmıştır. Sağlık yöneticilerinin dönüşümcü, otantik, etkileşimci liderlik gibi liderlik davranışları belirlenmeye çalışılmıştır. Yapılan araştırmalarda sağlık yöneticilerinin liderlik özellikleri dönüşümcü, paternalist, demokratik ve stratejik liderlik olarak belirlenirken, hemşirelerin liderlikleri özellikleri bunlara ilave olarak otantik, görev odaklı, hizmetkar ve etkileşimci liderlik olarak tespit edilmiştir. Sağlık kurumlarındaki yöneticilerin liderlik özellikleri ve algıları, örgütsel güven düzeyi, örgütsel bağlılık düzeyi, çalışan motivasyonu, zaman yönetimi gibi değişkenler açısından değerlendirilmiştir. Çalışmaya dahil edilen araştırmaların özellikleri Tablo 1 'de verilmiştir.

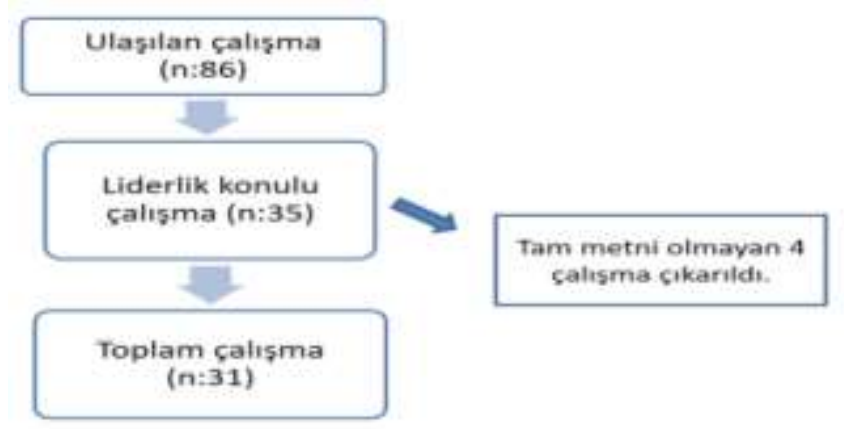

Şekil 1: Çalışmaların Seçilme Sürecini Gösteren Akış Şeması

\section{Tartışma}

Günümüz bilgi ve teknoloji çağı her alanda olduğu gibi sağlık kurumlarında da değişimi gerekli kılmıştır. Sağlık yöneticileri en iyi hizmeti sunabilmek için çağın gerektirdiği liderlik özellikleri doğrultusunda izleyicilerini harekete geçirmek, onlara klavuzluk yapmak ve model olmak zorundadır (Alıcı, 2018). Artık yönetici geleneksel liderlik anlayışının çok ötesinde sadece çözüm odaklı değil, vizyon ve gelecek 
hakkında öngörü sahibi olan, yenilikçi, üretken sıfatları ile çağdaş liderlik özelliklerine sahip olabilmelidir. Sağlık yöneticilerinin liderlik özelliklerinin incelenmesi amacıyla yapılan bu çalışma sonucunda, elde edilen bulgular literatür bilgileri ışığında tartışılmıştır.

Sağlık kurumlarının, kendilerine başvuran hastalara kaliteli ve etkili bir hizmet vermeleri gerekmektedir. Bunun içinde sürekli kendilerini yenilemek ve geliştirmek zorunlulukları vardır. Bu bağlamda en önemli faktör ise sağlık kurumlarındaki yöneticilerdir. Çünkü onlar örgütlerini ve ekiplerini geleceğe taşıyan etkin kişilerdir. Bu sebeple sağlık yöneticilerinin göstermiş olduğu liderlik özellikleri önemlidir (Alıcı, 2018; Arık, 2018).

Sağlık hizmeti temelinde insanı, ekip çalışmasını, empatiyi, aktif iletişimi, şefkati içinde barındırır. Bu nedenle sağlık çalışanlarının buna uygun davranış göstermesi gerekmektedir. Kurumuna, çalışma arkadaşlarına ve hastalara faydalı olan bir lider, diğer kişiler tarafından daha kolay benimsenir ve izlenir (Alıcl, 2018). Bu sebeple sağlık kurumlarındaki yöneticilerin liderlik özelliklerinin ve çalışanları tarafından nasıl algılandığının bilinmesi önemlidir. Literatürde, ülkemizde sağlık kurumlarında yönetici pozisyonunda bulunanların liderlik özelliklerini inceleyen az sayıda çalışmaya rastlanmıştır. Araştırma sonuçlarımız doğrultusunda bu alanda 1998-2018 yılları arasında otuz bir çalışmanın yapıldığı tespit edilmiştir. Bu çalışmaların yarısından fazlası hemşirelik disiplininde yapılmış olup, diğer sağlık disiplinleri alanındaki yöneticilerin liderlik özelliklerini inceleyen çok az sayıda çalışma tespit edilmiştir.

Dönüşümcü lider, izleyicilerinin gereksinimlerini, inançlarını, değer yargılarını değiştiren kişidir. Dönüşümcü liderler, kendilerini izleyenler için rol model olurken, kendilerini adama düzeylerini yükselmektedir. $\mathrm{Bu}$ liderler, örgütsel yaşamı anlamlı hale getirirken, çalışanlarının kendilerine güven duymalarını sağlamaktadır (Koçel, 2003). Çalışma sonuçlarımızda sağlık kurumlarındaki yöneticilerin en çok dönüşümcü liderlik özelliği taşıdığı saptanmıştır. Yılmaz ve Kantek'in (2016) yaptığı çalışmada yönetici hemşirelerin dönüşümcü ve iş odaklı liderlik tarzlarına sahip olduğu ortaya konulmuştur. Sağlık kurumlarındaki kalite ve performans değerlendirme politikalarının, hemşirelik hizmetleri vizyonlarının, hemşirelik mesleğinde lisanslaşma ve uz- 
manlaşmanın artmasının dönüşümcü liderlik tarzının artmasında etkili olduğu düşünülmektedir.

Yapılan bir çok çalışma göstermiştir ki sağlık lideri sağlık örgütlerinin gelişimi ve değişimi açısından çok önemlidir. Sağlık liderinin örgütte veya kendi içinde bulunduğu ekip üzerinde yarattığ1 güven çok önemlidir. Ayrıca sağlık liderleri örgütteki diğer elemanlar için rol model durumundadır. Kendisini değiştiren ve sürekli yenileyen bir lider ancak etkili bir rol model olmak durumunda olacaktır. Bütün bunları dikkate aldığımızda iyi bir sağlık lideri; hiç kimsenin etkisi ve baskısı altında kalmadan çalışabilen, işbirlikçi, etik kuralları bilen ve uyan, etrafına güven duygusu veren, kendine güvenen, herkesi dinleyen ve görüşlerini dikkate alan, diğerlerine saygı gösteren, kendini geliştiren, yeniliklere açık, öğretebilen, diğer ekiplerle işbirliği içerisinde olan ve onlarla çalışmaktan çekinmeyen, çok yönlü çalışabilen özelliklere sahip olmalıdır (Gün ve Aslan,2018).

\section{Sonuç ve öneriler}

Yapılan literatür incelemesinde sağlık kurumlarındaki yönetici pozisyonundaki kişilerin en çok dönüşümcü liderlik, en az ise paternalist liderlik özelliği taşıdığı belirlenmiştir. Araştırma sonuçları sağlık kurumlarındaki yöneticilerin liderlik becerilerini geliştirmenin gerekliliğini ortaya koymaktadır. Fakat konuyla ilgili az sayıda yapılmış çalışma bulunmaktadır. Mevcut durumun daha objektif olarak ortaya konulmasına, sağlık alanındaki yöneticilerin liderlik özelliklerinin daha detaylı olarak incelenmesine gereksinim vardır. Sağlık sisteminde değişim çok hızlı olmaktadır. Sağlık yöneticilerinin değişimlere ayak uydurabilmesi, günceli yakalayabilmeleri için etkili ve etkin klinik liderlere gereksinim olduğu düşünülmektedir. Sağlık kurumlarında arzu edilen hizmetin sunulması, hasta memnuniyetinin ve hasta bakımında kalitenin arttırılması için sağlık yöneticilerinin liderlik becerilerini geliştirmeye yönelik, hizmet içi eğitim programları ve lisans eğitiminde liderlik konulu ders müfredatlarının oluşturulması önerilebilir. Ayrıca sağlık kurumlarındaki yöneticilerin liderlik özelliklerini belirlemeye yönelik multidisipliner çalışma ekipleriyle, nitel ve nicel çalışmaların yapılması önerilebilir. 
Araştırmanın Sınırlılıkları: Literatür incelemesinde sadece YÖK Tez veri tabanındaki çalışmalar esas alınmış olup, diğer veri tabanları kullanılmamıştır. Ayrıca incelenen çalışmalar sadece ulusal yayın özelliğini taşımaktadır. 


\section{EXTENDED ABSTRACT Leadership Characteristics of Health Managers * \\ Hamide Nur Çevik Özdemir - Rahman Çakır - Rıdvan Küçükali Afyon Kocatepe University, Giresun University, Atatürk University}

Leadership in health is a process in which health managers influence other health care workers to achieve specific goals in providing care and treatment to patients or healthy people. Clinical leadership is the ability of clinicians in a health institution or a department to strive for a better general or one-to-one service delivery to the patient, and the initiative to change policies, procedures and systems through this effort (Budak \& Özer, 2017). Nowadays, it is expected to show leadership behaviors from managers at all levels of health services due to factors such as developing health institutions, competitiveness in health, and privatization. Leadership characteristics of health managers are an important factor in individual and corporate success (Duygulu and Kubilay, 2008). Every institution and individual has a leadership cencept of their own as well as the ways to implement it.Nowadays, it is expected to show leadership behaviors from managers at all levels of health services due to factors such as developing health institutions, competitiveness in health, and privatization. Leadership characteristics of health managers are an important factor in individual and corporate success (Duygulu and Kubilay, 2008).When all the definitions as regards leadership are examined, such terms as effect, vision, the power to influence, process, orientation and mission come to the fore (Yavuz, 2015). Unless a successful manager can influence positively the other individuals working in the same institution, it is inevitable that some problems will be encountered in the workplace.Management and leadership are of great importance in the provision of health services. Health institutions and health systems are large and have complicated structures. For this reason, the personnel providing health services need to cooperate, work in harmony and be coordinated by the managers. In order for the contruction of cooperation and its sustainability, managers are expected to actively show and use their leadership talents and qualities (Ardahan and Konal, 2017). In these institutions, the people who are expected to be influential in increasing 
the harmony and constructing coordination among the personnel are health leaders. As the positive leadership behaviours displayed by the managers in health institutions increase, the influence on the performance, work satisfaction and service quality of health workers also becomes positive. Managerial processes and policies provide a new point of view to the health environment through successful leadership applications, and create useful environments for both the patients and the workers by increasing the quality in health institutions (Lombardi, 2017). In this regard, it is possible to mention a lot of leadership types. In studies carried out on health leadership, in particular, one of the most important leadership types to come to the fore is transformative leadership. Transformative leadership is the most required and influential type in periods when transformations in a community happen suddenly, and in crisis environments where socio-economic problems tend to increase (Gedikoğlu, 2015). Especially in such periods and atmosphere, transformative leadership becomes essential for the provision of demands coming from outside, and adopting and implementing positive examples and applications of other institutions. For the same reason, interactive leadership is also important. While a transformative leader is expected to catch up with the new developments in health applications, procedures, new visions and models, an interactive leader deals more specifically with the inner structure of the instituions, such as coordination among the different parts and departments, work satisfaction, health care service quality and the problems and performances of the workers.An interactive leader watch the other workers, evaluate their performances, and decide to what extent they can do their duties and responsibilities successfully. In the end of his/her evaluation, s/he appreciates the successful personnel and awards their performance, while s/he spots unsuccessful personnel, specifies the reasons lying behind their inefficieny and finds solutions for it. When we take into consideration that any minor mistake may lead to very serious consequences, the importance of educating health personnel becomes more apparent (Gedikoğlu, 2015). In this regard, the importance of interactive leadership with a view to educationg health personnel increases.This study is a cross-sectional descriptive literature review. For data collection, the data coding form prepared by Kartal and Kantek (2015) was used as a reference; a standard data summary form was deve- 
loped for data summary, and data received in the study were analyzed in SPSS program. For each study in the data summary form, the author of the study, year of publication, type, sample size, location, questionnaires and forms were coded.Research results reveal the necessity of developing leadership skills of managers in health institutions. However, there is not a sufficient number of studies on the subject and it is necessary to present the current situation more objectively and examine the leadership characteristics of the managers in the field of health in more detail.

\section{Kaynakça / References}

Ada, Ş., ve Küçükali, R. (2018). Türk Eğitim sistemi ve okul yönetimi. Genişletilmiş 5. Baskı. Ankara:Anı Yayıncılık.

Alıc1, F.(2018). Hemşirelerin yönetici hemşirelerin hizmetkar liderliğine ilişkin algıları ve örgütsel bağlılık düzeyleri. Yüksek Lisans Tezi, Marmara Üniversitesi Sağlık Bilimleri Enstitüsü, İstanbul.

Alptekin, S. (2018). Bir üniversite hastanesinde çalışan hemşirelerin yönetici hemşireleri ile ilgili ruhsal liderlik algılarının belirlenmesi. Yüksek Lisans Tezi, Marmara Üniversitesi Sağlık Bilimleri Enstitüsü. İstanbul.

Ardahan M. ve Konal E. (2017). Hemşirelikte yöneticilik ve liderlik. Gümüşhane Üniversitesi Să̆lık Bilimleri Dergisi. 6(1), 140-147.

Arık, S. (2018). Yönetici Hemşirelerin hizmetkar liderlik düzeylerinin değerlendirilmesi. Yüksek Lisans Tezi, Karadeniz Teknik Üniversitesi Sağlık Bilimleri Enstitüsü. Trabzon.

Budak, F. ve Özer, Ö. (2017). Külttürlerarası hemşirelik bağlammnda klinik liderliğin önemi. 16.11.2018 tarihindehttps://www.researchgate.net/publication/321 371470_Kulturlerarasi_Hemsirelik_Baglaminda_Klinik_Liderligi n_Onemi_adresinden erişilmiştir.

Cemaloğlu, N.(2013). Liderlik. (Ed. S. Özdemir). Eğitim yönetiminde kuram ve uygulama içinde (s.131-177), Ankara:Pegem Akademi Yayınları.

Duygulu, S. ve Kubilay, G. (2008). Yönetici hemşirelerin ve birlikte çalıştıkları hemşirelerin liderliğie ilişkin değerlendirmeleri ve yönetici hemşirelerin sahip oldukları liderlik özellikleri. Să̆lık Bilimleri Fakültesi Hemşirelik Dergisi. 18(5), 1-15. 
Ergün, E. veÇelik, S. (2015).Yöneticilerin görev ve çalışan odaklı liderlik davranışları ve hemşirelerin iş tatmini, örgütsel bağlllık ve iş stresi arasındaki ilişki. F.N.Hem.Derg. 23(3), 203-214.

Gedikoğlu,T.(2015).Liderlik ve okul yönetimi. Ankara:Anı Yayıncılık.

Gün,İ. ve Aslan,Ö.(2018).Liderlik kuramları ve sağlık işletmelerinde liderlik. Sağllk ve Hemşirelik Yönetim Dergisi, 5(3),217-226.

Koçel, T. (2003). İsletme yöneticiliği. Dokuzuncu Basım. İstanbul:Beta Basım Yayın Dağıtım.

Korkmaz, F., Gökdeniz, İ. ve Zorlu,K.(2018).Paternalist liderlik davranışının örgütsel özdeşleşme üzerindeki etkisinde çalışanların işe tutkunluk düzeylerinin aracılık rolü.İsletme Araştırmaları Dergisi. 10(3), 950-973.

Lombardi, J. (2017). The road to leadership in SPN. Journal of Pediatric Nursing, 34, 96-97.

Serinkan C. ve İpekçi İ. (2005). Yönetici hemşirelerde liderlik ve liderlik özelliklerine ilişkin bir araştırma. Süleyman Demirel Üniversitesi İktisadi ve İdari Bilimler Fakültesi Dergisi, 10, 281-294.

Şahinli, S.(2018). Sağlık yöneticilerinin stratejik liderlik davranışlarının kriz yönetimi üzerine etkisi: İstanbul İli özel hastaneler uygulaması. Yüksek Lisans Tezi, Sakarya Üniversitesi Sağlik Bilimleri Enstitüsü.Sakarya.

Yavuz, M. (2015).Öğrenme liderliği. Ankara:Anı Yayıncılık.

Yıldırım, D. (2018). Hemşirelerin yönetici hemşirelerin otantik liderliğine ilişkin algzları ve örgütsel güven düzeyleri. Yüksek Lisans Tezi, Marmara Üniversitesi Sağlık Bilimleri Enstitüsü. İstanbul.

Yıldırım, Ö. (2013). Yönetici Hemşirelerin Algılanan Liderlik Tarzlarının Yetki Devretme Düzeylerine Etkisi. Haliç Üniversitesi Sağlık Bilimleri Enstitüsü Yüksek Lisans Tezi. İstanbul.

Yllmaz H. ve Kantek F. (2016).Türkiye'deki yönetici hemşirelerin liderlik tarzlar1: Literatür inceleme. Journal of Health and Nursing Management, 2(3), 110-117. 


\section{Kaynakça Bilgisi / Citation Information}

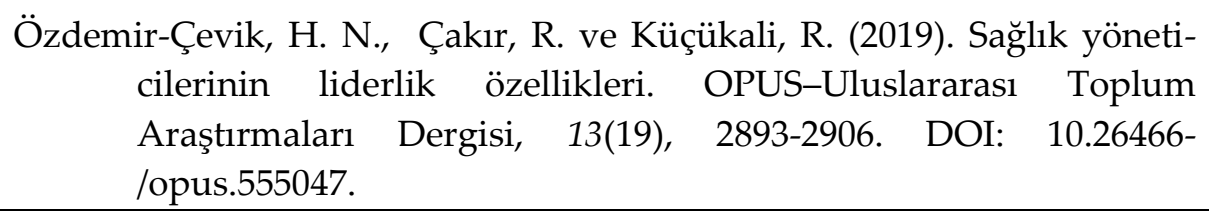

\section{Ek-1}

Tablo 1:Sağlık Yöneticilerinin Liderlik Özelliklerini İnceleyen Çalışmalar ve Özellikleri

\begin{tabular}{|c|c|c|c|c|c|c|c|}
\hline No & Yazar & Y1l1 & $\begin{array}{l}\text { Çalışm } \\
\text { anın } \\
\text { Türü }\end{array}$ & $\begin{array}{l}\text { Çalışmanın } \\
\text { Yeri ve } \\
\text { Çalışma } \\
\text { Grubu } \\
\text { (Örneklemi) } \\
\end{array}$ & $\begin{array}{l}\text { Çalışmanın } \\
\text { Yapıldığı } \\
\text { Kurum }\end{array}$ & $\begin{array}{l}\text { Yöntem ve } \\
\text { Ölçme } \\
\text { Aracı }\end{array}$ & Sonuçlar \\
\hline 1 & Alıc1 & 2018 & $\begin{array}{c}\text { Yüksek } \\
\text { Lisans } \\
\text { Tezi }\end{array}$ & $\begin{array}{l}\text { İstanbul } \\
329 \text { Hemşire }\end{array}$ & $\begin{array}{l}\text { Kamu } \\
\text { Hastaneleri }\end{array}$ & $\begin{array}{l}\text { Tanımlayıcı } \\
\text { *Anket formu } \\
\text { *Hizmetkar } \\
\text { Liderlik Ölç. } \\
\text { *Örgütsel } \\
\text { Bağlllık Ölç. }\end{array}$ & $\begin{array}{l}\text { Hemşireler, yönetici } \\
\text { hemşirelerini } \\
\text { orta düzeyde hizmetkar } \\
\text { lider olarak algılamaktadır. }\end{array}$ \\
\hline 2 & Alptekin & 2018 & $\begin{array}{l}\text { Yüksek } \\
\text { Lisans } \\
\text { Tezi }\end{array}$ & $\begin{array}{l}\text { İstanbul } \\
379 \text { Hemşire }\end{array}$ & $\begin{array}{l}\text { Üniversite } \\
\text { Hastanesi }\end{array}$ & $\begin{array}{l}\text { Tanımlayıcı } \\
{ }^{*} \text { Anket formu } \\
{ }^{*} \text { Ruhsal } \\
\text { Liderlik Ölç. }\end{array}$ & $\begin{array}{l}\text { Hemşirelerin, yönetici } \\
\text { hemşirelerinde orta düzey- } \\
\text { de ruhsal liderlik davranışı } \\
\text { algıladıklarını belirtmiştir. }\end{array}$ \\
\hline 3 & Arık & 2018 & $\begin{array}{l}\text { Yüksek } \\
\text { Lisans } \\
\text { Tezi }\end{array}$ & $\begin{array}{l}\text { Trabzon } \\
311 \text { Hemşire }\end{array}$ & $\begin{array}{l}\text { Üniversite } \\
\text { Hastanesi } \\
\text { Kamu Has- } \\
\text { tanesi }\end{array}$ & $\begin{array}{l}\text { Tanımlayııı } \\
{ }^{*} \text { Hizmetkar } \\
\text { Liderlik Ölç. }\end{array}$ & $\begin{array}{l}\text { Hemşirelerin, yönetici ve } \\
\text { sorumlu hemşirelerinde } \\
\text { daha fazla hizmetkar lid- } \\
\text { erlik tarzını algıladıkları } \\
\text { saptanmıştır. }\end{array}$ \\
\hline 4 & İspirli & 2018 & $\begin{array}{l}\text { Yüksek } \\
\text { Lisans } \\
\text { Tezi }\end{array}$ & $\begin{array}{l}\text { İstanbul } \\
146 \text { Yönetici } \\
\text { Hemşire }\end{array}$ & $\begin{array}{l}\text { Üniversite } \\
\text { Hastaneleri }\end{array}$ & $\begin{array}{l}\text { Tanımlayıcı } \\
\text { *Empatik } \\
\text { Eğilim Ölç. } \\
{ }^{*} \text { Kişilerarası } \\
\text { Prob. Çöz.Env. }\end{array}$ & $\begin{array}{l}\text { Yönetici Hemşirelerin } \\
\text { liderlik özelliklerinin ve } \\
\text { empatik eğilimlerinin } \\
\text { yüksek olduğu belirtilmiştir. }\end{array}$ \\
\hline 5 & Şahinli & 2018 & $\begin{array}{l}\text { Yüksek } \\
\text { Lisans } \\
\text { Tezi }\end{array}$ & $\begin{array}{l}\text { İstanbul } \\
385 \text { Hastane } \\
\text { Yöneticisi }\end{array}$ & $\begin{array}{l}\text { Özel } \\
\text { Hastaneler }\end{array}$ & $\begin{array}{l}\text { Tanımlayıcı } \\
\text { *Stratejik } \\
\text { Liderlik Ölç. } \\
\text { *Kriz Yönetimi } \\
\text { Ölç. }\end{array}$ & $\begin{array}{l}\text { Sağlık yöneticilerinin } \\
\text { stratejik liderlik davranışları } \\
\text { ile kriz yönetim düzeyleri } \\
\text { arasında negatif yönlü bir } \\
\text { ilişski bulunmuştur. }\end{array}$ \\
\hline 6 & Yildırım & 2018 & $\begin{array}{l}\text { Yüksek } \\
\text { Lisans } \\
\text { Tezi }\end{array}$ & $\begin{array}{l}\text { İ̀stanbul } \\
321 \text { Hemşire }\end{array}$ & $\begin{array}{l}\text { Kamu } \\
\text { Hastaneleri }\end{array}$ & $\begin{array}{l}\text { Tanımlayıcı } \\
{ }^{*} \text { Otantik Lid- } \\
\text { erlik Ölç. } \\
{ }^{* O ̈ r g u ̈ t s e l ~} \\
\text { Güven Ölç. }\end{array}$ & $\begin{array}{l}\text { Otantik liderlik algisı } \\
\text { yüksek olan hemşirelerin } \\
\text { örgütsel güven düzeyleri } \\
\text { yüksek bulunmuştur. }\end{array}$ \\
\hline
\end{tabular}

Not: Dergi yayın politikası gereği çalışmaların yalnızca bir bölümü verilmiştir. 